\title{
Human Reaction to Threat: Examining the Interplay Between Personality Dispositions and Situational Features
}

\author{
Tsachi Ein-Dor, Adi Perry-Paldi \\ Interdisciplinary Center Herzliya, Israel
}

\begin{abstract}
Objective: Research on human reaction to threats has been limited and focused either on the effects of situational features or on the effects of personality dispositions. In the present research, we examined the processes by which personality (specifically attachment orientations) qualifies the effects of situational features on reactions to threat scenarios. Method: In Study 1, 307 Israeli participants completed a self-report measure of attachment orientations (anxiety and avoidance), and reported on the first action that they are likely to take on various threat scenarios. In Study 2, 295 non-Israeli participants completed self-report measures of attachment orientations (anxiety and avoidance), fear of negative evaluation, and body sensations (the latter two served as covariates), and reported on their reactions to threat scenarios as in Study 1. Results: Results indicated that attachment anxiety qualified the effects of situational features to increase the likelihood of sentinel (e.g., yelling) and fear-related behaviors (e.g., running away). Avoidance qualified the effects of situational features to increase the likelihood of rapid-responder (e.g., attacking), fear-related, and anxiety-related (e.g., risk assessment) reactions. Conclusions: Results are discussed in relation to the complex interplay between personality and situational features on humans' behaviors when dealing with threats and danger.
\end{abstract}

Keywords: attachment, social defense theory, anxiety, avoidance, situational features, threat, danger

The past speaks to us in a thousand voices, warning and comforting, animating and stirring to action. Felix Adler (1876)

\section{Introduction}

Since the dawn of man, humans have faced threats and danger as was alluringly portrayed in cave paintings (e.g., Campbell, 1986). Research on human reaction to threats has been limited, however, Blanchard and colleagues (D. C. Blanchard, Hynd, Minke, Minemoto, \& R. J. Blanchard, 2001; R. J. Blanchard, R. J. Blanchard, \& Hori, 1989) have used animal models to explore mammals' defensive behaviors when dealing with threats. They revealed that people respond to situational features, as the degree of dangerousness and clarity of the threat, in a parallel way to the defense patterns of rats and mice. Ein-Dor and colleagues (Ein-Dor, in press; Ein-Dor, Mikulincer, Doron, \& Shaver, 2010; Ein-Dor, Mikulincer, \& Shaver, 2011a, 2011b; Ein-Dor \& Orgad, 2012; Ein-Dor \& Perry, 2012, in press) have suggested SDT (social defense theory) (Ein-Dor et al., 2010) - an extension to Bowlby's attachment theory $(1973 ; 1980 ; 1982$ - to examine the way personality dispositions (specifically, attachment orientations) affect people's reactions to various threats (also see Perkins 
\& Corr, 2006). To date, however, the interplay between situational features and personality remains unexplored. In the present research, we aim to bridge this gap by examining the processes by which personality qualifies the effects of situational features on reactions to threat scenarios.

Animal models on reactions to threats and danger indicate that threats such as predators elicit several distinct defensive behaviors among laboratory rodents: flight, freeze, defensive threat, defensive attack, and risk assessment (see Blanchard, 1997 for a review). These behaviors are greatly influenced by features of both the threat and the situation in which it is encountered. For example, when rats and mice come upon a highly dangerous situation in which the nature of the threat is clear (e.g., when facing a predator), they tend to flight if an escape route is available, and to freeze if it is not. The distance from the threat also qualifies their actions: A threatening stimulus tends to elicit a defensive attack when in close proximity, but a defensive threat (i.e., particular vocalizations) when further away (Blanchard et al., 1989). Risk assessment behaviors may also be evoked in situations in which the threat is not clearly present but only cued (e.g., the odor of a predator; Blanchard et al., 1989). Gray and McNaughton (2000; see also McNaughton \& Corr, 2004) argue that mammals' defensive behaviors could be classified into two clusters that represent the action of two brain systems, one controlling anxiety, the other fear. Fear has the function of moving the animal away from danger, and involves fight, flight, and freeze. Anxiety has the function of moving the animal toward danger. It mainly comprises risk assessment. The differences in the reactivity of these systems give rise to personality differences in reactions to threats and danger (Perkins \& Corr, 2006). In 2001, Blanchard and colleagues examined the validity of using rodent defensive reactions to model human behavior. To measure these behaviors without exposing individuals to real danger, they developed a threat scenario questionnaire. Specifically, participants were asked to report on the first action that they are likely to take in scenarios that varied along dimensions of dangerousness, escapability, distance between threat and target, ambiguity of threat, and availability of a place of concealment or protection. These dimensions comprise the situational features that are known to alter rodent defensive behavior. They found that human defensive reactions are affected by situational features in a similar way to rodent defensive reactions (elicited by actual threat). Perkins and Corr (2006) have replicated and extended these findings by revealing that personality, specifically the general sensation of tension and stress (i.e., trait anxiety; see Spielberger, Gorsuch, \& Lushene, 1970), is linked with individual differences in the directionality of people's actions (i.e., towards a threat or away from it). Recently, Ein-Dor and colleagues introduced social defense theory (Ein-Dor et al., 2010) as one possible and more comprehensive way to link personality with people's reactions in times of threat and danger.

SDT is based on attachment theory (Bowlby, 1973; 1980; 1982), which posits that human beings and many nonhuman primates are born with an innate psychobiological system (the attachment behavioral system) that emerged as an adaptation over the course of mammalian evolution because it increased the likelihood of survival during infancy - a crucial period for protection and support given that humans are born with immature capacities for locomotion, feeding, and defense. Because infants require a long period of care and protection, they are born with a repertoire of behaviors that maintain proximity to others who help them cope with threats and regulate distress. Although the attachment system is crucial during the early years of life, Bowlby (1988) assumed that it is active over the entire life span and is manifested inadults' tendencies to seek proximity and support when threatened or distressed (Hazan \& Zeifman, 1999). Many studies have shown that the system is indeed active during adulthood and affects many aspects of psychological and social functioning (see Mikulincer \& Shaver, 2007 for an extensive review). For instance, research indicates that actual or symbolic 
threats cause adults to seek physical proximity to close others or to activate mental representations of attachment figures (Mikulincer, Birnbaum, Woddis, \& Nachmias, 2000; Mikulincer, Gillath, \& Shaver, 2002; Mikulincer, Hirschberger, Nachmias, \& Gillath, 2001).

Bowlby (1973) also proposed that a person's attachment behavioral system is gradually shaped by experiences with attachment figures and the memories of these experiences in the form of working models of self and others. These models eventually result in a fairly stable attachment "style" or orientation - a person's characteristic pattern of relational expectations, emotions, and behaviors (Fraley \& Shaver, 2000). Social and personality psychologists generally conceptualize adult attachment orientations as regions in a continuous two-dimensional space (e.g., Brennan, Clark, \& Shaver, 1998). The dimension of attachment-related anxiety reflects the extent to which a person worries that others will not be available or helpful in times of need. Anxious individuals exaggerate their sense of vulnerability and insistently call on others for help and care, sometimes to the point of being intrusive (e.g., Feeney \& Noller, 1990). The second dimension, attachment-related avoidance, reflects the extent to which a person distrusts relationship partners' goodwill, strives to maintain independence, and relies on deactivating strategies for dealing with threats and negative emotions (e.g., Fraley \& Shaver, 1997). Attachment security is defined by low scores on both anxiety and avoidance. Secure people generally cope with threats by relying on internal resources developed with the help of security-enhancing attachment figures or by effectively seeking support from others or collaborating with them (Shaver \& Mikulincer, 2002).

SDT posits that each of the major attachment orientations (secure, anxious, and avoidant) confers unique adaptive advantages that increase the inclusive fitness (see Hamilton, 1964) of individuals. Secure people tend to remain emotionally stable in the face of threats and to calmly and efficiently coordinate and lead group members' problem-solving efforts (e.g., Rom \& Mikulincer, 2003). People who are high in attachment anxiety are more likely to demonstrate sentinel behaviors - noticing ambiguous signs of threat, and warning others about the threat (i.e., making yelling, threatening to yell, and begging for help more likely in times of need; see also Ein-Dor \& Orgad, 2012). For example, research has indicated that people with high scores on attachment anxiety had greater mental access to sentinel-related schemas (Ein-Dor et al., 2011a); when compared with their more secure counterparts, individuals high in attachment anxiety recognized sentinel-related sentences quicker and with greater accuracy than more secure individuals (Study 2). When exposed to an experimentally created threatening situation (a room gradually filling with smoke because of a malfunctioning computer), the most anxious person in a group was the most likely to detect the presence of the threat (Study 6), which contributed to the effectiveness of their social group when dealing with the threat (Ein-Dor et al., 2011b). Anxious individuals were also less willing to be delayed on their way to deliver a warning message after they were led to believe that they accidently activated a computer virus that erased an experimenter's computer (Ein-Dor \& Orgad, 2012). Moreover, people high in attachment anxiety were more accurate in detecting social-oriented threats as deceitful statements, and were better poker players-a social game that is partially based on players' ability to detect cheating (Ein-Dor \& Perry, in press).

Avoidant individuals are accustomed to looking out for their own interests and taking care of themselves, even if this sometimes occurs at other people's expense (e.g., Collins \& Read, 1990; Feeney \& Collins, 2001; Van Lange, Otten, De Bruin, \& Joireman, 1997). Thus, they are more likely to rely on self-protective fight-or-flight reactions in times of danger, without hesitating or needing to deliberate with other group members. For example, an avoidant person may enact the quickest protective maneuver (approach motivation) or quickly notice the best escape route from a threatening situation (avoidance motivation), reactions that 
Ein-Dor and colleagues called "rapid responder behaviors" (i.e., making attacking, threatening to attack, and running away more likely in times of need; Ein-Dor et al., 2010). Research has indeed indicated that people with high scores on attachment avoidance had greater mental access to rapid-responder-related schemas (Ein-Dor et al., 2011a); when compared with their more secure counterparts, individuals high in attachment avoidance were more likely to process rapid-responder-schema information in a deep way and to generate more inferences and conjectures based on this information (Study 5). In experimentally created threatening situation (a room gradually filling with smoke because of a malfunctioning computer), attachment-related avoidance was associated with speedier escape responses to the danger once it was detected and with the effectiveness of groups when dealing with threats (Ein-Dor et al., 2011b).

Despite the promising results of Blanchard and colleagues (on the effects of situational features; Blanchard et al., 2001) and those of Ein-Dor and colleagues (on the effects of personality dispositions; see Ein-Dor, in press; and Ein-Dor \& Perry, 2012 for reviews), there is still no information about whether personality dispositions interact with situational features to affect people's action tendencies in times of threat and danger. Looking into this matter is the purpose of the studies reported here.

Research stemming from SDT has linked attachment anxiety with a greater tendency to demonstrate sentinel-related behaviors in times of need as yelling, threatening to yell, and begging for help, and attachment avoidance with a lesser tendency for presenting these behaviors. Therefore, we hypothesize that people's attachment orientations would interact with the situational features to either increase the likelihood of these actions (in the case of attachment anxiety) or decrease this likelihood (in the case of attachment avoidance). In addition, people who are relatively high in attachment anxiety adopt hyperactivating strategies of affect regulation in times of threat or stress, which results in exaggerated threat appraisal, almost regardless of the actual threat (Cassidy \& Kobak, 1988; Mikulincer et al., 2000). Moreover, they react to threats by moving away from danger while minimizing distance from others (e.g., Feeney \& Noller, 1990). Therefore, we predict that attachment anxiety would interact with the situational features to increase the likelihood of fear-related behaviors (Gray \& McNaughton, 2000) as running away and hiding. SDT posits that attachment avoidance is linked with self-protective fight-or-flight behaviors. Therefore, we also expect attachment avoidance to interact with the situational features and to increase the likelihood of fear-related behaviors (as in flight).

Research stemming from SDT has linked attachment avoidance with a greater tendency to demonstrate rapid-responder-related behaviors in times of need as attacking and threatening to attack, and attachment anxiety with a lesser tendency to present these behaviors. Therefore, we hypothesize that people's attachment orientations would interact with the situational features to either increase the likelihood of these actions (in the case of attachment avoidance) or decrease this likelihood (in the case of attachment anxiety). In addition, people who are relatively high in attachment avoidance tend to deal with stress on their own (a strategy that Bowlby, 1973, called "compulsive self-reliance") and refrain from appraising events as threatening and from expressing distress, anxiety, or despair, even if they are forced to experience these negative emotions (see Mikulincer \& Shaver, 2007 for a review). Therefore, we predict that attachment avoidance would interact with the situational features to increase the likelihood of anxiety-related behaviors (Gray \& McNaughton, 2000) as looking for a weapon and assessing the risk of the situation. In comparison, anxious people are over-dependent on others in times of need, and tend to appraise threats as extreme and their own coping resources as deficient (e.g., Alexander, Feeney, Hohaus, \& Noller, 2001). Accordingly, we hypothesize that attachment anxiety would interact with the situational features to decrease the likelihood of anxiety-related behaviors. 


\section{Study 1}

In Study 1, we examined associations between attachment anxiety and avoidance scores, on one hand, and action tendencies in the face of various real-life threats, on the other. Participants completed a self-report measure of attachment anxiety and avoidance, and then were asked to report on the first action that they were likely to take on different demanding situations, which differed in the five features that are known to alter human (Blanchard et al., 2001; Perkins \& Corr, 2006) and rodent (Blanchard et al., 1989) defensive behavior: (1) magnitude of threat; (2) escapability; (3) distance; (4) ambiguity; and (5) opportunity for concealment. We hypothesize that attachment anxiety would qualify the effects of the situational features on people's action tendencies by increasing the prevalence of sentinel-related reactions as well as fear-related behaviors (i.e., behaviors that orient people away from threats; Gray \& McNaughton, 2000). We also predict that attachment anxiety would qualify the links between situational features and people's action tendencies by decreasing the frequency of rapid-responder-related reactions as well as anxiety-related behaviors (i.e., behaviors that orient people toward threats). Conversely, we hypothesized that attachment avoidance would be linked with an increase in the likelihood to adopt rapid-responder-related reactions as well as anxiety (i.e., approach) and fear-related (i.e., avoidance) behaviors. Attachment avoidance was also hypothesized to be linked with a decrease in the likelihood to demonstrate sentinel-related reactions.

Because people's appraisals regarding their reactions to threats may depend on their current sensation of anxiety and tension, we examined our predictions while controlling for participants' state anxiety. In addition, research has indicated that men and women differed in their responses to threats, such that women were more inclined to yell and call for help than men, whereas men were more likely to attack and struggle than women (Blanchard et al., 2001; Perkins \& Corr, 2006). Therefore, we also included the measure of gender in our model.

\section{Method}

Participants. Three hundred and seven Israeli undergraduates (165 women and 142 men, ranging in age from 19 to $41, M=23.57, S D=2.51$ ) participated in the study in exchange for credit in psychology courses.

Materials and procedure. The study was presented as a research on perception of threats. The data were gathered using Qualtrics Labs, Inc. software, Version 2012 of the Qualtrics Research Suite. After electronically signing a consent form, participants completed two randomly ordered psychological measures. Attachment orientations were assessed with a Hebrew version of the ECR (experiences in close relationships scales) (Brennan et al., 1998). Participants rated the extent to which each item was descriptive of their feelings in close relationships on a 7-point scale ranging from "Not at all" (1) to "Very much" (7). Eighteen items assessed attachment anxiety (e.g., "I worry about being abandoned") and 18 assessed avoidance (e.g., "I prefer not to show a partner how I feel deep down"). The reliability and validity of these scales have been repeatedly demonstrated (beginning with Brennan et al., 1998; see Mikulincer \& Shaver, 2007 for a review). In our study, Cronbach $\alpha$ s were 0.90 for the anxiety items and 0.87 for the avoidance items. Mean scores were computed for each scale, and the two scores were weakly correlated, $r_{(305)}=0.17, p=0.003$.

State anxiety was assessed with STAI (the State-Trait Anxiety Inventory) (Spielberger et al., 1970). Participants rated the extent that they are feeling anxious at the present moment (i.e., state anxiety; e.g., "I feel frightened"; $\alpha=0.93,20$ items) on a 4-point scale ranging from "Not at all" (1) to "Very much so" (4). Summed scores were calculated for each participant, such that higher scores reflect greater state anxiety. State 
anxiety was moderately linked with both attachment anxiety $\left(r_{(305)}=0.47, p<0.001\right)$ and avoidance $\left(r_{(305)}=\right.$ $0.30, p<0.001)$.

After completing these questionnaires, participants were asked to read 12 scenarios comprising threatening events (Blanchard et al., 2001; e.g., "You are walking alone in an isolated but familiar area when a menacing stranger suddenly jumps out of the bushes to attack you"). The scenarios varied along dimensions of dangerousness, escapability, distance between threat and target, ambiguity of threat, and availability of a place of concealment or protection. To quantify the position of each scenario along these dimensions, we conducted a pre-test in which 34 Israeli undergraduates (19 women and 15 men, ranging in age from 21 to 54, $M=25.09$, $S D=5.36$ ) were asked to rate each scenario with respect to each dimension (see mean scores as a supplementary material). Participants were instructed to choose the first action that they were likely to take from a list of 10 common responses (e.g., "hide", "yell", "attack"), although they were permitted to write in another response if their first choice was not on the list (for a total of $0.6 \%$ of the responses). After completing this task, participants completed a socio-demographic questionnaire and were thanked.

\section{Results and Discussion}

Predicting sentinel- and fear-related action tendencies. In this section, we examined whether attachment orientations (anxiety and avoidance) qualify the effects of situational features (dangerousness, escapability, distance between threat and target, ambiguity of threat, and availability of a place of concealment or protection) on participants' tendency to undertake sentinel (yell/scream, threaten to scream, beg/plead/negotiate) and fear-related (run, hide) actions. Given the dichotomous nature of participants' responses (e.g., in each scenario, participants either chose to hide (coded as 1) or not to hide (coded as 0)), multilevel logistic regression (by Hierarchical Nonlinear Modeling; Raudenbush, Bryk, \& Congdon, 2004) was used. At the within-subject level, we introduced the situational features scores as predictors; at the between-subject level, we added the attachment anxiety and avoidance scores and the interactions between attachment orientations and the situational features as predictors. We also introduced the measures of state anxiety and gender $(0=$ women, $1=$ men $)$ as covariates. Unstandardized HLM coefficients and odd ratios are presented in Table 1.

Regarding the situational features, the analyses revealed that the likelihood to yell, beg, and/or run away was higher in more dangerous situations, in events in which the chances to escape were low, and when the nature of threat was clear. Conversely, as the distance from the threat increased, and as the possibilities for concealment became more abundant, than the likelihood to yell, beg, and/or run away was lower. The opposite pattern of results was obtained regarding the likelihood to hide and/or to threaten to scream: It increased when the distance from the threat was high and when concealment was possible. It also increased when the danger was low, when the chances of escaping were high, and when the nature of the threat was ambiguous.

Regarding the personality dispositions, the analyses revealed that the probability of people high on attachment anxiety to choose begging or running away as their first response was significantly higher than people lower on that domain. In addition, attachment anxiety qualified the effects of the situational features on people's likelihood to yell and/or to threaten to scream as first responses. To visualize the observed interaction, we used the logistic regression results to plot the predicted response profile separately for people high $(+1 S D)$ and low (-1 SD) on attachment anxiety (Aiken \& West, 1991). As can be seen in Figure 1 (top panel), the 
likelihood of people low on attachment anxiety (and therefore more secure with respect to this domain) to yell decreased as the distance from the threat increased. Conversely, the likelihood of people high on attachment anxiety to yell was significantly higher than the probability of their more secure counterparts, and was not affected by the distance from the threat (i.e., remained high regardless of the distance). A complimentary pattern of results was revealed regarding the likelihood to threaten to scream (see Figure 1, middle panel): People low on attachment anxiety were not likely to threaten to scream even if their chances of escaping the scene were low. Conversely, the probability of people high on attachment anxiety to threaten to scream was significantly higher than that of their more secure counterparts, and it became even higher as their chances of being caught by the threat increased.

Table 1

Unstandardized HLM Coefficients and Odd Ratios for the Effects of Attachment Orientations, and Situational Features on Participants' Sentinel- and Fear-Related Action Tendencies (Study 1)

\begin{tabular}{|c|c|c|c|c|c|c|c|c|c|c|}
\hline & \multicolumn{6}{|c|}{ Sentinel-related } & \multicolumn{4}{|c|}{ Fear-related } \\
\hline & \multicolumn{2}{|c|}{ Yell } & \multicolumn{2}{|c|}{ Threaten to scream } & \multicolumn{2}{|c|}{ Beg } & \multicolumn{2}{|c|}{ Run away } & \multicolumn{2}{|c|}{ Hide } \\
\hline & $b$ & $\operatorname{Exp}(b)$ & $b$ & $\operatorname{Exp}(b)$ & $b$ & $\operatorname{Exp}(b)$ & $b$ & $\operatorname{Exp}(b)$ & $b$ & $\operatorname{Exp}(b)$ \\
\hline Dangerousness & $0.62^{* * *}$ & 1.86 & $-0.70^{* * *}$ & 0.50 & $0.52^{* *}$ & 1.69 & $0.73^{* * *}$ & 2.08 & $-1.42^{* * *}$ & 0.24 \\
\hline Being caught & $0.51^{* * *}$ & 1.67 & $-0.71^{* * *}$ & 0.50 & $0.49^{*}$ & 1.63 & $0.19^{* * *}$ & 1.21 & $-1.25^{* * *}$ & 0.29 \\
\hline Distance & $-0.69^{* * *}$ & 0.50 & $0.44^{* *}$ & 1.55 & $-1.10^{* * *}$ & 0.33 & $-0.42^{* * *}$ & 0.66 & $1.44^{* * *}$ & 4.21 \\
\hline Clarity of the threat & $0.88^{* * *}$ & 2.40 & $-0.59^{* *}$ & 0.56 & $0.50^{* *}$ & 1.65 & $0.85^{* * *}$ & 2.34 & $-1.82^{* *}$ & 0.16 \\
\hline Concealment & $-0.70^{* * *}$ & 0.49 & $0.69^{* * *}$ & 1.99 & $-0.61^{* *}$ & 0.54 & $-0.28^{* * *}$ & 0.77 & $1.55^{* * *}$ & 4.72 \\
\hline Anxiety & 0.10 & 1.11 & 0.06 & 1.06 & $0.34^{*}$ & 1.40 & $0.08^{\sim}$ & 1.08 & 0.04 & 1.04 \\
\hline Avoidance & -0.10 & 0.91 & -0.10 & 0.91 & -0.25 & 0.78 & -0.02 & 0.98 & 0.08 & 1.08 \\
\hline State anxiety & -0.001 & 1.00 & -0.01 & 0.99 & 0.01 & 1.00 & 0.01 & 1.01 & 0.01 & 1.01 \\
\hline Gender & $-1.91^{* * *}$ & 0.15 & $-0.76^{* *}$ & 0.47 & -0.18 & 0.84 & $-0.62^{* * *}$ & 0.54 & $-3.00^{* * *}$ & 0.05 \\
\hline Dangerousness $\mathrm{X}$ anxiety & -0.06 & 0.94 & 0.25 & 1.29 & 0.15 & 1.16 & -0.01 & 0.99 & -0.24 & 0.79 \\
\hline Being caught $\mathrm{X}$ anxiety & -0.06 & 0.94 & $0.40^{*}$ & 1.49 & 0.05 & 1.05 & -0.03 & 0.97 & -0.25 & 0.78 \\
\hline Distance $\mathrm{X}$ anxiety & $0.17^{*}$ & 1.17 & -0.24 & 0.79 & -0.02 & 0.98 & -0.03 & 0.97 & 0.27 & 1.50 \\
\hline Clarity of the threat $\mathrm{X}$ anxiety & -0.07 & 0.93 & 0.13 & 1.13 & 0.08 & 1.08 & 0.02 & 1.02 & 0.06 & 1.06 \\
\hline Concealment $\mathrm{X}$ anxiety & 0.08 & 1.08 & -0.28 & 0.69 & -0.04 & 0.96 & 0.01 & 1.00 & 0.37 & 1.31 \\
\hline Dangerousness $\mathrm{X}$ avoidance & -0.13 & 0.87 & -0.30 & 0.74 & 0.01 & 1.01 & $0.07^{\sim}$ & 1.07 & 0.06 & 1.07 \\
\hline Being caught $\mathrm{X}$ avoidance & -0.07 & 0.92 & -0.27 & 0.76 & 0.07 & 1.07 & 0.05 & 1.05 & 0.03 & 1.03 \\
\hline Distance $\mathrm{X}$ avoidance & 0.06 & 1.06 & 0.08 & 1.08 & -0.10 & 0.90 & 0.02 & 1.02 & 0.01 & 1.00 \\
\hline Clarity of the threat $\mathrm{X}$ avoidance & -0.14 & 0.87 & -0.27 & 0.77 & 0.05 & 1.05 & 0.05 & 1.06 & -0.09 & 0.91 \\
\hline Concealment $\mathrm{X}$ avoidance & 0.13 & 1.13 & 0.23 & 1.26 & -0.09 & 0.91 & -0.03 & 0.97 & 0.01 & 1.01 \\
\hline
\end{tabular}

Notes. $\sim p<.07,{ }^{*} p<0.05,{ }^{* *} p<0.01,{ }^{* * *} p<0.001 . \operatorname{Exp}(b)$ relates to odd ratios. $D F(293,3676)$. Tolerance scores were above 0.4 .

The analyses also revealed that attachment avoidance qualified the effect of the dangerousness of the threat on the likelihood to choose running away as the first response (see Figure 1, bottom panel): The likelihood of people low on attachment avoidance (and therefore more secure with respect to this domain) to run away became higher as the dangerousness of the threat increased. This tendency was significantly stronger among people high on attachment avoidance.

Predicting rapid-responder and anxiety-related action tendencies. In this section, we examined whether attachment orientations (avoidance and anxiety) qualify the effects of situational features on participants' tendency to undertake rapid-responder (attack, threaten to attack) and anxiety-related (risk assessment, look for a weapon) actions. Unstandardized HLM coefficients and odd ratios are presented in Table 2. 

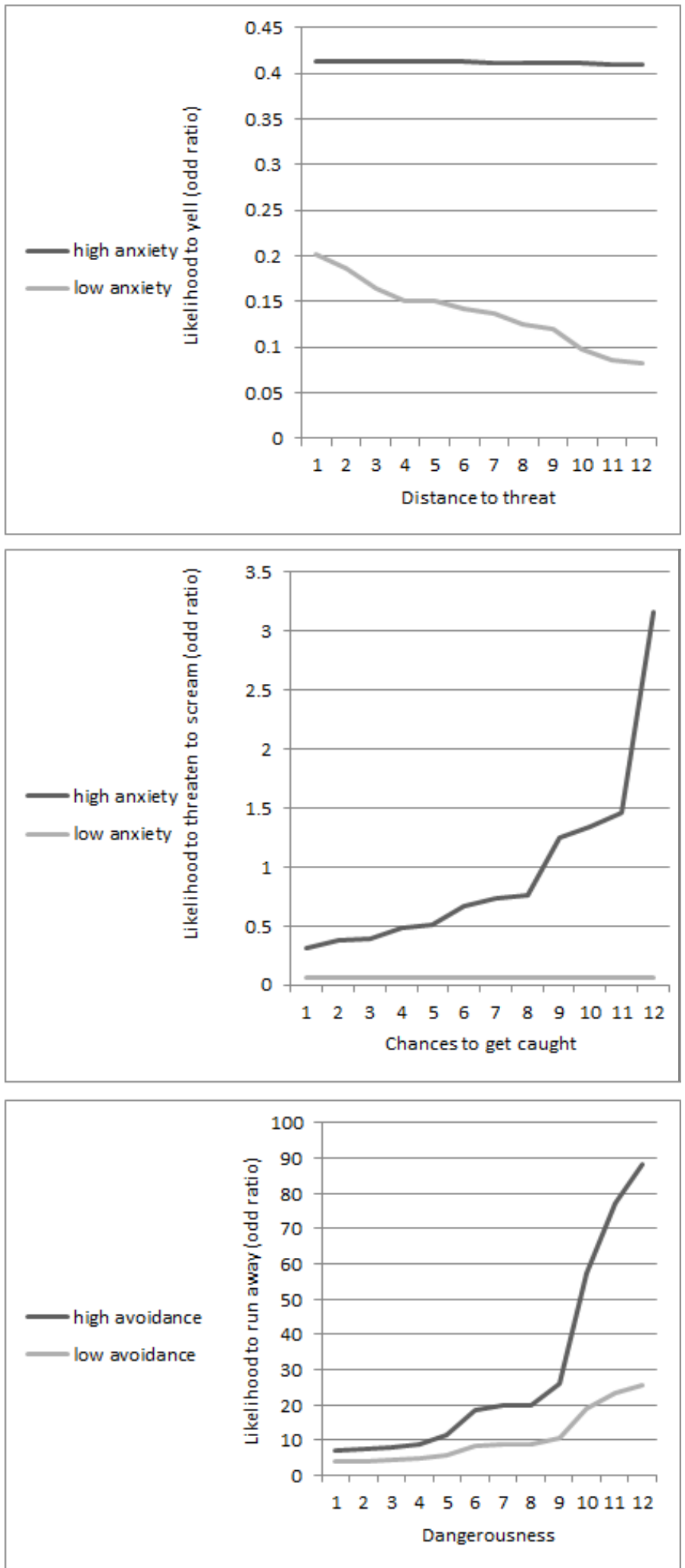

Figure 1. The effect of attachment anxiety and distance to threat on the likelihood to yell (top); the effect of anxiety and escapability on the likelihood to threaten to scream (middle); the effect of avoidance and dangerousness on the likelihood to run away (bottom). 
Table 2

Unstandardized HLM Coefficients and Odd Ratios for the Effects of Attachment Orientations, and Situational Features on Participants' Rapid-Responder-and Anxiety-Related Action Tendencies (Study 1)

\begin{tabular}{|c|c|c|c|c|c|c|c|c|}
\hline & \multicolumn{6}{|c|}{ Rapid-responder-related } & \multirow{2}{*}{\multicolumn{2}{|c|}{$\begin{array}{l}\text { Anxiety-related } \\
\text { Risk assessment }\end{array}$}} \\
\hline & \multicolumn{2}{|c|}{ Attack } & \multicolumn{2}{|c|}{ Threaten to attack } & \multicolumn{2}{|c|}{ Look for a weapon } & & \\
\hline & $b$ & $\operatorname{Exp}(b)$ & $b$ & $\operatorname{Exp}(b)$ & $b$ & $\operatorname{Exp}(b)$ & $b$ & $\operatorname{Exp}(b)$ \\
\hline Dangerousness & $1.29^{* * *}$ & 3.65 & 0.05 & 1.06 & $-0.57^{* * *}$ & 0.56 & $-1.01^{* * *}$ & 0.36 \\
\hline Being caught & $2.09^{* * *}$ & 8.06 & 0.19 & 1.21 & $-0.64^{* * *}$ & 0.53 & $-0.73^{* * *}$ & 0.48 \\
\hline Distance & $-3.03^{* * *}$ & 0.05 & $-0.70^{* * *}$ & 0.50 & $1.38^{* * *}$ & 3.97 & $0.34^{* * *}$ & 1.41 \\
\hline Clarity of the threat & $1.21^{* * *}$ & 3.36 & $0.19^{\sim}$ & 1.21 & $-0.49^{* * *}$ & 0.61 & $-1.26^{* * *}$ & 0.28 \\
\hline Concealment & $-1.75^{* * *}$ & 0.17 & $-0.29^{*}$ & 0.75 & $0.89^{* * *}$ & 2.43 & $0.60^{* * *}$ & 1.83 \\
\hline Anxiety & $-0.24^{*}$ & 0.79 & -0.05 & 0.94 & -0.01 & 1.00 & -0.03 & 0.97 \\
\hline Avoidance & $0.28^{* *}$ & 1.32 & $0.25^{*}$ & 1.29 & -0.16 & 0.86 & 0.01 & 1.01 \\
\hline State anxiety & -0.01 & 0.99 & 0.02 & 1.02 & -0.01 & 0.99 & -0.02 & 0.99 \\
\hline Gender & $1.56^{* * *}$ & 4.78 & $1.59^{* * *}$ & 4.93 & $0.68^{* * *}$ & 1.97 & $0.66^{* * *}$ & 1.94 \\
\hline Dangerousness $\mathrm{X}$ anxiety & 0.01 & 1.01 & -0.14 & 0.87 & $-0.25^{* *}$ & 0.78 & 0.05 & 1.05 \\
\hline Being caught $\mathrm{X}$ anxiety & 0.10 & 1.11 & -0.05 & 0.95 & -0.15 & 0.86 & 0.05 & 1.06 \\
\hline Distance $X$ anxiety & $-0.49^{* *}$ & 0.61 & -0.14 & 0.87 & 0.05 & 1.05 & -0.01 & 0.99 \\
\hline Clarity of the threat $X$ anxiety & 0.04 & 1.04 & -0.15 & 0.86 & $-0.20^{*}$ & 0.82 & -0.01 & 0.99 \\
\hline Concealment $\mathrm{X}$ anxiety & -0.03 & 0.97 & -0.01 & 1.00 & 0.17 & 1.18 & -0.04 & 0.96 \\
\hline Dangerousness $\mathrm{X}$ avoidance & -0.11 & 0.90 & 0.10 & 1.10 & -0.12 & 0.89 & 0.10 & 1.10 \\
\hline Being caught $\mathrm{X}$ avoidance & -0.05 & 0.95 & -0.07 & 0.93 & -0.17 & 0.84 & 0.01 & 1.01 \\
\hline Distance $\mathrm{X}$ avoidance & -0.10 & 0.91 & 0.19 & 1.21 & 0.15 & 1.16 & 0.07 & 1.07 \\
\hline Clarity of the threat $\mathrm{X}$ avoidance & -0.11 & 0.89 & 0.08 & 1.08 & -0.16 & 0.85 & $0.17^{*}$ & 1.19 \\
\hline Concealment $\mathrm{X}$ avoidance & 0.01 & 1.01 & 0.06 & 1.06 & $0.22^{\sim}$ & 1.24 & -0.01 & 0.99 \\
\hline
\end{tabular}

Notes. ${ }^{\sim} p<0.07,{ }^{*} p<0.05,{ }^{* *} p<0.01,{ }^{* * *} p<0.001 . D F(293,3676)$. Tolerance scores were above 0.4 .

Multilevel logistic regression analyses indicated that the likelihood to choose to attack as a first response increased as the dangerousness of the situation became higher, the chances of being caught became greater, and the nature of the threat - clearer. It was also higher when the threat was closer and when concealment was unavailable. An opposite pattern of results was revealed regarding the likelihood to look for a weapon and to assess the risk of the situation: It was the highest when the danger was low, when escapability was high, and when the nature of the threat was ambiguous. It was also the highest when the threat was distant and when concealment was abundant. Finally, the likelihood of people to choose to threaten to attack as their first response became higher when the nature of the threat became clearer, the distance to the threat became closer, and concealment chances became lower.

Regarding the personality dispositions, the analyses revealed that the probability of people high on attachment avoidance to choose attacking or threaten to attack as their first response was significantly higher than people lower on that domain. In addition, attachment avoidance qualified the effects of the situational features on people's likelihood to look for a weapon and/or to assess the risk of the situation as first responses. As can be seen in Figure 2 (top panel), the likelihood of people low on attachment avoidance (and, therefore, more secure with respect to this domain) to look for a weapon was low and was not affected by the availability of concealment places. Conversely, the probability of people high on attachment avoidance to look for a weapon was significantly higher than their more secure counterparts, and increased as concealment places became more feasible. In addition, although the likelihood of people to assess the risk of the situation became 
lower as the nature of the threat became clearer, the tendency for risk assessment was significantly stronger among people high on attachment avoidance than people lower on that domain (see Figure 2, bottom panel).

Regarding attachment anxiety, the analyses indicated that the likelihood of people high on attachment anxiety to choose attacking as a first response was significantly lower than people lower on that domain. This latter tendency was also dependent on the distance from the threat. As can be seen in Figure 3 (top panel), the likelihood of people low on attachment anxiety (and, therefore, more secure with respect to this domain) to choose attacking decreased as the distance from the threat increased. Conversely, the probability of people high on attachment anxiety to attack was significantly lower than their more secure counterparts, and remained lower regardless of the distance from the threat (i.e., even when the threat was the closest). Attachment anxiety also qualified the effects of the dangerousness of the situation and the clarity of the threat on people's likelihood to look for a weapon. As can be seen in Figure 3 (middle and bottom panels), the probability of people low on attachment anxiety to look for a weapon became lower as the danger became higher and the nature of the threat - clearer. The likelihood of people high on attachment anxiety to look for a weapon was significantly lower than their more secure counterparts, and was less affected by the situational features.

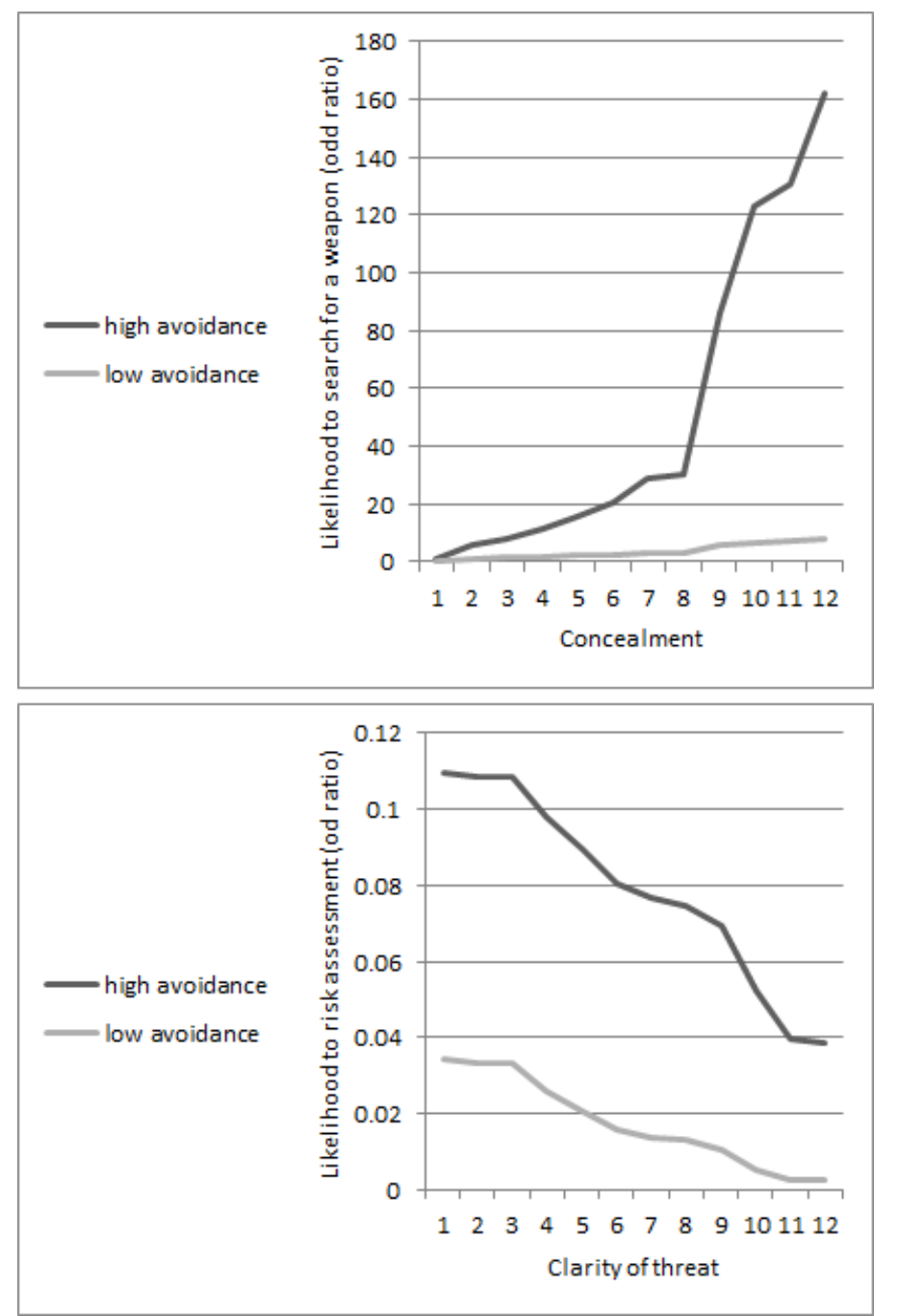

Figure 2. The effect of attachment avoidance and concealment on the likelihood to search for a weapon (top); the effect of avoidance and clarity of threat on the likelihood for risk assessment (bottom). 

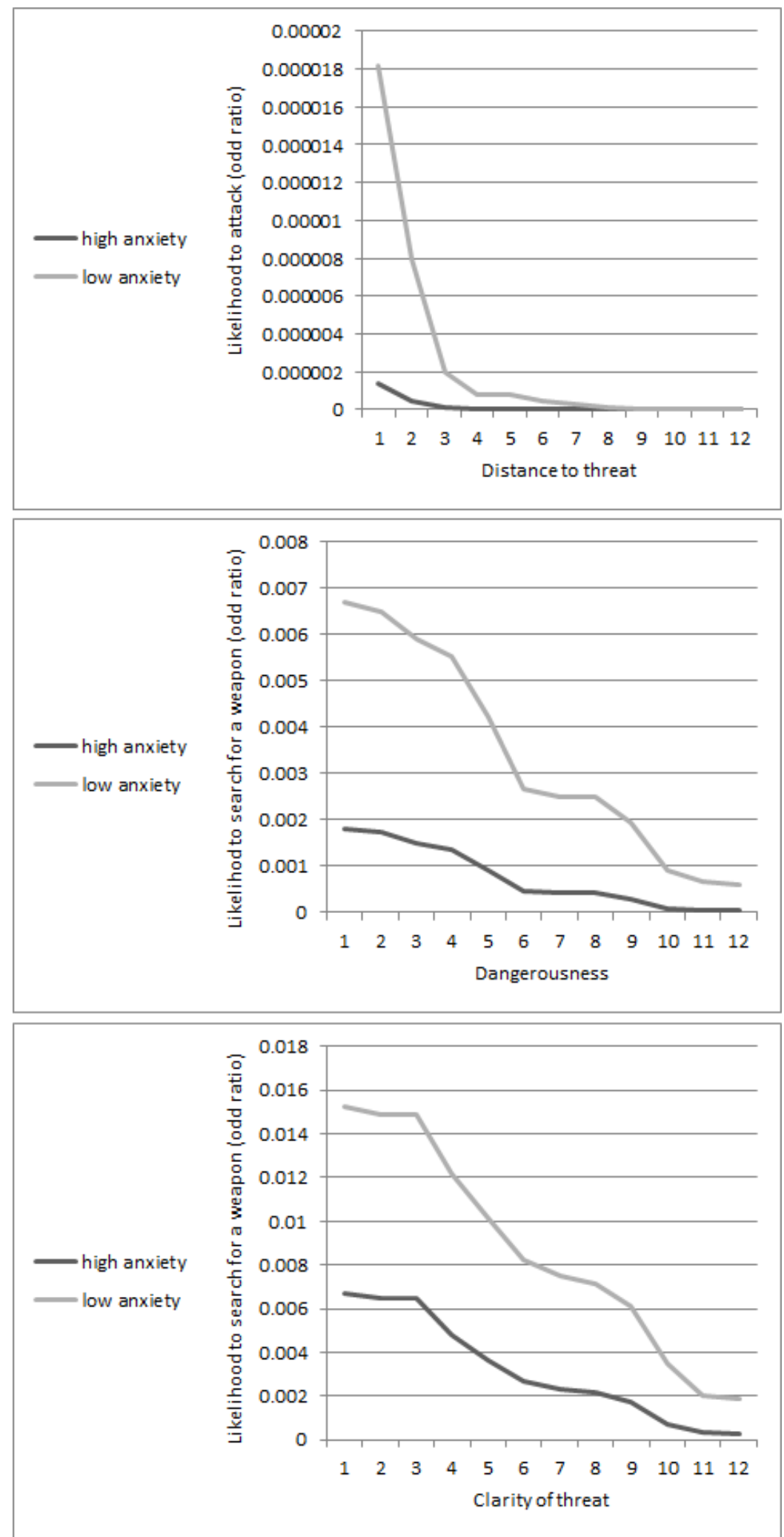

Figure 3. The effect of attachment anxiety and distance to threat on the likelihood to attack (top); the effect of anxiety and dangerousness on the likelihood to search for a weapon (middle); and the effect of anxiety and clarity of threat on the likelihood to search for a weapon (bottom). 
Finally, the analyses indicated that women were significantly more likely than men to choose sentineland/or fear-related responses (i.e., yell, threaten to scream, run away, and/or hide) as their first reactions, whereas men were significantly more likely than women to choose rapid-responder- and/or anxiety-related responses (i.e., attack, threaten to attack, look for a weapon, and/or risk assessment).

Overall, the findings supported our predictions. Attachment anxiety either increased the likelihood of choosing sentinel-related responses (in the case of begging) or interacted with the situational features to heightened people's probability of choosing these responses (in the case of yelling and threatening to scream). It was also linked with people tendency to run away (a fear-related response) regardless of the situational feature, but not with the tendency to hide. In addition, attachment anxiety decreased the likelihood of choosing rapid-responder-related responses (specifically attacking and looking for a weapon). These effects were significant even after controlling for state anxiety and gender.

The opposite pattern of results was obtained regarding attachment avoidance: It either increased the likelihood of choosing rapid-responder-related responses (in the case of attacking and threatening to attack) or interacted with the situational features to heightened people's probability of choosing these responses (in the case of looking for a weapon). It also qualified the effect of the situational features on people's tendency for risk assessment (an anxiety-related response) by increasing the likelihood of choosing this response. Finally, attachment avoidance interacted with the situational features to heightened people's probability of choosing running away as a first response (a fear-related response). This latter tendency is in line with social defense theory because people high on attachment avoidance "are likely to rely on self-protective fight-or-flight reactions in times of danger" (Ein-Dor et al., 2010, p. 132).

Study 1 was conducted on Israeli participants who lived throughout their lives in a country often engulfed by political violence (e.g., Bar-Tal, Halperin, \& Oren, 2010). Because cultural differences were documented in people's responses to emotional-provoking events (see Mesquita \& Frijda, 1992 for a review), it may be important to examine whether Study 1's pattern of results generalizes to people from other cultures. In addition, in Study 1, we controlled for participants' state anxiety, which relates to both attachment anxiety and avoidance. People's appraisals regarding their reactions to threats may be depended not only on their current sensation of anxiety and tension, however. For example, people's concerns with being evaluated unfavorably by others affect their conformity, self-presentation, self-serving attributions, social anxiety, attitude change, compliance, and social facilitation (see Schlenker, 1980 for an extensive review). In addition, people's appraisals regarding their reactions to threats may be influenced by their body sensations (e.g., Casey, Oei, Newcombe, \& Kenardy, 2004), and not only by their psychological sensation of tension. Because attachment anxiety and avoidance relate to fear of negative evaluations and to exacerbate body sensations, it may be important to examine our prediction while controlling for these variables. We designed Study 2 to address these shortcomings.

\section{Study 2}

In Study 2, we examined our prediction that attachment orientations would qualify the effects of situational features on people's action tendencies among participants from various cultures, and while controlling for fear of negative evaluation and body sensations.

\section{Method}

Participants. Two hundred and ninety five undergraduates (182 women and $113 \mathrm{men}$, ranging in age from 17 to $68, M=28.77, S D=12.05$ ) from the international school of the Interdisciplinary Center, Herzliya, 
participated in the study in exchange for credit in psychology courses. The study was conducted on students who spend no more than six months in Israel prior the onset of the research. Participants were from North America (43.8\%), Western Europe (36.5\%), South Africa (17.7\%), or Australia (2.1\%).

Materials and procedure. The study was presented as a research on perception of threats. The data were gathered using Qualtrics Labs, Inc. software, Version 2012 of the Qualtrics Research Suite. After electronically signing a consent form, participants completed three randomly ordered psychological measures. Attachment orientations were assessed with the ECR (Brennan et al., 1998), as in Study 1. Cronbach $\alpha$ s were 0.71 for the anxiety items and 0.77 for the avoidance items. Mean scores were computed for each scale, and the two scores were moderately correlated, $r_{(293)}=0.36, p<0.001$.

Fear of negative evaluation was assessed with the 12-item brief version of the FNE (Fear of Negative Evaluation) (Leary, 1983) scale. Participants rated the extent to which each item was descriptive of their feelings regarding others' evaluations (e.g., "I am usually worried about what kind of impression I make") on a 5-point scale ranging from "Not at all" (1) to "Very much" (5). Cronbach $\alpha$ was 0.95 . Fear of negative evaluation was moderately linked with both attachment anxiety $\left(r_{(293)}=0.47, p<0.001\right)$ and avoidance $\left(r_{(293)}=0.37, p<0.001\right)$.

Body sensations were assessed with the 17-item Body Sensations Questionnaire (BSQ; Chambless, Caputo, Bright, \& Gallagher, 1984). Participants rated the extent to which each sensation (e.g., "Pressure in chest") is anxiety provoking on a 5-point scale ranging from "Not frightened or worried by this sensation" (1) to "Extremely frightened by this sensation" (5). Cronbach $\alpha$ was 0.92 . Body sensations were moderately linked with both attachment anxiety $\left(r_{(293)}=0.37, p<0.001\right)$ and avoidance $\left(r_{(293)}=0.30, p<0.001\right)$.

After completing these questionnaires, participants were asked to read 12 scenarios comprising a present or potential threatening event, and to choose the first action that they were likely to take from a list of 10 common responses, as in Study 1. After completing this task, participants completed a socio-demographic questionnaire and were thanked.

\section{Results and Discussion}

Predicting sentinel- and fear-related action tendencies. In this section, we examined whether attachment orientations (anxiety and avoidance) qualify the effects of situational features (dangerousness, escapability, distance between threat and target, ambiguity of threat, and availability of a place of concealment or protection) on participants' tendency to undertake sentinel (yell/scream, threaten to scream, beg/plead/negotiate) and fear-related (run, hide) actions. At the within-subject level of the multilevel logistic regression analyses, we introduced the situational features scores as predictors; at the between-subject level, we added the attachment anxiety and avoidance scores and the interactions between attachment orientations and the situational features as predictors. We also introduced the measures of fear of negative evaluation, body sensations, and gender $(0=$ women, $1=$ men) as covariates. Unstandardized HLM coefficients and odd ratios are presented in Table $3^{1}$.

Regarding the personality dispositions, the analyses revealed that the probability of people high on attachment anxiety to choose begging as their first response was significantly higher than people lower on that domain. In addition, attachment anxiety qualified the effects of the situational features on people's likelihood to yell, threaten to scream, and/or running away as first responses. As can be seen in Figure 4 (top panel), the likelihood of people low on attachment anxiety (and therefore more secure with respect to this domain) to yell was low, although it increased, at least to some extent, as the situation became more dangerous. The likelihood

\footnotetext{
${ }^{1}$ For simplicity reasons, we did not refer to the effects of the situational features.
} 
of people high on attachment anxiety to yell was significantly higher than the probability of their more secure counterparts, and was affected by the dangerousness of the situation to much greater extent ${ }^{2}$. People low on attachment anxiety were also not likely to threaten to scream, even if the distance from the threat was high. Conversely, the probability of people high on attachment anxiety to threaten to scream was significantly higher than that of their more secure counterparts, and it became greater as the distance from the threat increased (see Figure 4, middle panel). Similarly, people low on attachment anxiety were not likely to run away, even if the distance from the threat was high. Conversely, the probability of people high on attachment anxiety to run away was affected by the distance from the threat such that it became much higher as the distance became greater (see Figure 4, bottom panel) ${ }^{3}$.

Table 3

Unstandardized HLM Coefficients and Odd Ratios for the Effects of Attachment Orientations, and Situational Features on Participants' Sentinel- and Fear-Related Action Tendencies (Study 2)

\begin{tabular}{|c|c|c|c|c|c|c|c|c|c|c|}
\hline & \multicolumn{6}{|c|}{ Sentinel-related } & \multicolumn{4}{|c|}{ Fear-related } \\
\hline & \multicolumn{2}{|c|}{ Yell } & \multicolumn{2}{|c|}{$\begin{array}{c}\text { Threaten to } \\
\text { scream }\end{array}$} & \multicolumn{2}{|c|}{ Beg } & \multicolumn{2}{|c|}{ Run away } & \multicolumn{2}{|c|}{ Hide } \\
\hline & $b$ & $\operatorname{Exp}(b)$ & $b$ & $\operatorname{Exp}(b)$ & $b$ & $\operatorname{Exp}(b)$ & $b$ & $\operatorname{Exp}(b)$ & $b$ & $\operatorname{Exp}(b)$ \\
\hline Dangerousness & $0.28^{* * *}$ & 1.33 & 0.01 & 1.00 & $0.52^{* *}$ & 1.69 & $0.42^{* * *}$ & 1.53 & $-0.47^{* * *}$ & 0.62 \\
\hline Being caught & $0.33^{* * *}$ & 1.39 & 0.01 & 1.00 & $0.49^{* *}$ & 1.63 & $0.08^{*}$ & 1.09 & $-0.45^{* *}$ & 0.63 \\
\hline Distance & -0.11 & 0.89 & -0.10 & 0.91 & $-1.10^{* * *}$ & 0.33 & $-0.38^{* * *}$ & 0.68 & $0.84^{* * *}$ & 2.33 \\
\hline Clarity of the threat & $0.21^{* *}$ & 1.23 & 0.02 & 1.02 & $0.50^{* *}$ & 1.65 & $0.46^{* * *}$ & 1.59 & $-0.49^{* * *}$ & 0.61 \\
\hline Concealment & $-0.24^{* * *}$ & 0.79 & -0.01 & 0.99 & -0.08 & 0.93 & $-0.17^{* *}$ & 0.85 & $0.55^{* * *}$ & 1.74 \\
\hline Anxiety & 0.11 & 1.11 & 0.18 & 1.20 & $0.35^{*}$ & 1.41 & 0.05 & 1.06 & -0.20 & 0.82 \\
\hline Avoidance & 0.13 & 1.14 & 0.07 & 1.08 & $-0.22^{\sim}$ & 0.80 & 0.04 & 1.04 & $0.37^{*}$ & 1.45 \\
\hline Gender & $-0.98^{* * *}$ & 0.38 & -0.11 & 0.89 & 0.20 & 1.23 & $-0.44^{* *}$ & 0.65 & $-0.51 \sim$ & 0.60 \\
\hline Fear of negative evaluation & -0.01 & 1.00 & -0.02 & 0.98 & 0.01 & 1.00 & 0.01 & 1.00 & -0.02 & 0.98 \\
\hline Body sensations & $0.25^{*}$ & 1.28 & 0.09 & 1.09 & 0.18 & 1.19 & -0.08 & 0.92 & $0.37^{*}$ & 1.38 \\
\hline Dangerousness $\mathrm{X}$ anxiety & $0.26^{*}$ & 1.29 & -0.14 & 0.87 & 0.15 & 1.16 & 0.01 & 1.01 & $-0.65^{* * *}$ & 0.52 \\
\hline Being caught $X$ anxiety & $0.32^{* *}$ & 1.38 & -0.10 & 0.91 & 0.05 & 1.05 & 0.06 & 1.07 & $-0.57^{* *}$ & 0.57 \\
\hline Distance $\mathrm{X}$ anxiety & -0.17 & 0.85 & $0.32^{\sim}$ & 1.36 & -0.02 & .98 & -0.07 & 0.94 & $0.41^{*}$ & 1.51 \\
\hline Clarity of the threat $\mathrm{X}$ anxiety & $0.21^{*}$ & 1.23 & -0.12 & 0.89 & 0.08 & 1.08 & -0.03 & 0.97 & $-0.70^{* * *}$ & 0.50 \\
\hline Concealment $\mathrm{X}$ anxiety & $-0.29^{* *}$ & 0.75 & 0.18 & 1.20 & 0.20 & 1.23 & 0.01 & 1.01 & $0.55^{*}$ & 1.71 \\
\hline Dangerousness $\mathrm{X}$ avoidance & $-0.20^{*}$ & 0.82 & 0.03 & 1.03 & 0.01 & 1.01 & -0.04 & 0.96 & 0.03 & 1.03 \\
\hline Being caught $\mathrm{X}$ avoidance & $-0.25^{* *}$ & 0.78 & -0.13 & 0.88 & 0.07 & 1.07 & -0.05 & 0.95 & 0.02 & 1.02 \\
\hline Distance $\mathrm{X}$ avoidance & $0.19^{*}$ & 1.21 & 0.14 & 1.15 & -0.11 & 0.90 & -0.10 & 0.91 & -0.09 & 0.91 \\
\hline Clarity of the threat $\mathrm{X}$ avoidance & $-0.16^{*}$ & 0.85 & 0.10 & 1.10 & 0.05 & 1.05 & 0.05 & 1.08 & 0.04 & 1.04 \\
\hline Concealment $\mathrm{X}$ avoidance & $0.26^{* *}$ & 1.30 & 0.12 & 1.13 & -0.07 & 0.94 & -0.08 & 0.92 & -0.06 & 0.95 \\
\hline
\end{tabular}

Notes. $\sim p<0.07, * p<0.05, * * p<0.01, * * * p<0.001 . D F(287,3507)$. Tolerance scores were above 0.4 .

Regarding attachment avoidance, the analyses revealed that the probability of people high on attachment avoidance to choose begging as their first response was significantly lower than people lower on that domain. The likelihood to choose hiding, however, was significantly higher among people high in avoidance than among their more secure counterparts. The analyses also revealed that attachment avoidance qualified the effect

\footnotetext{
${ }^{2}$ Attachment anxiety also qualified the effects of escapability, clarity of threat, and distance from the threat on participants' likelihood to yell. The pattern of results was similar to the qualifying effect of anxiety on dangerousness.

${ }^{3}$ Attachment anxiety also qualified the effects of escapability, clarity of threat, distance from the threat, and concealment on participants' likelihood to run away. The pattern of results was similar to the qualifying effect of anxiety on dangerousness.
} 
of several situational features on the likelihood to choose yelling as a first response (see Figure 5, top panel) 4 . For example, the likelihood of people high on attachment avoidance to yell was significantly lower than that of people lower on that domain (and therefore more secure), and it became even less probable as the nature of the threat became clearer.
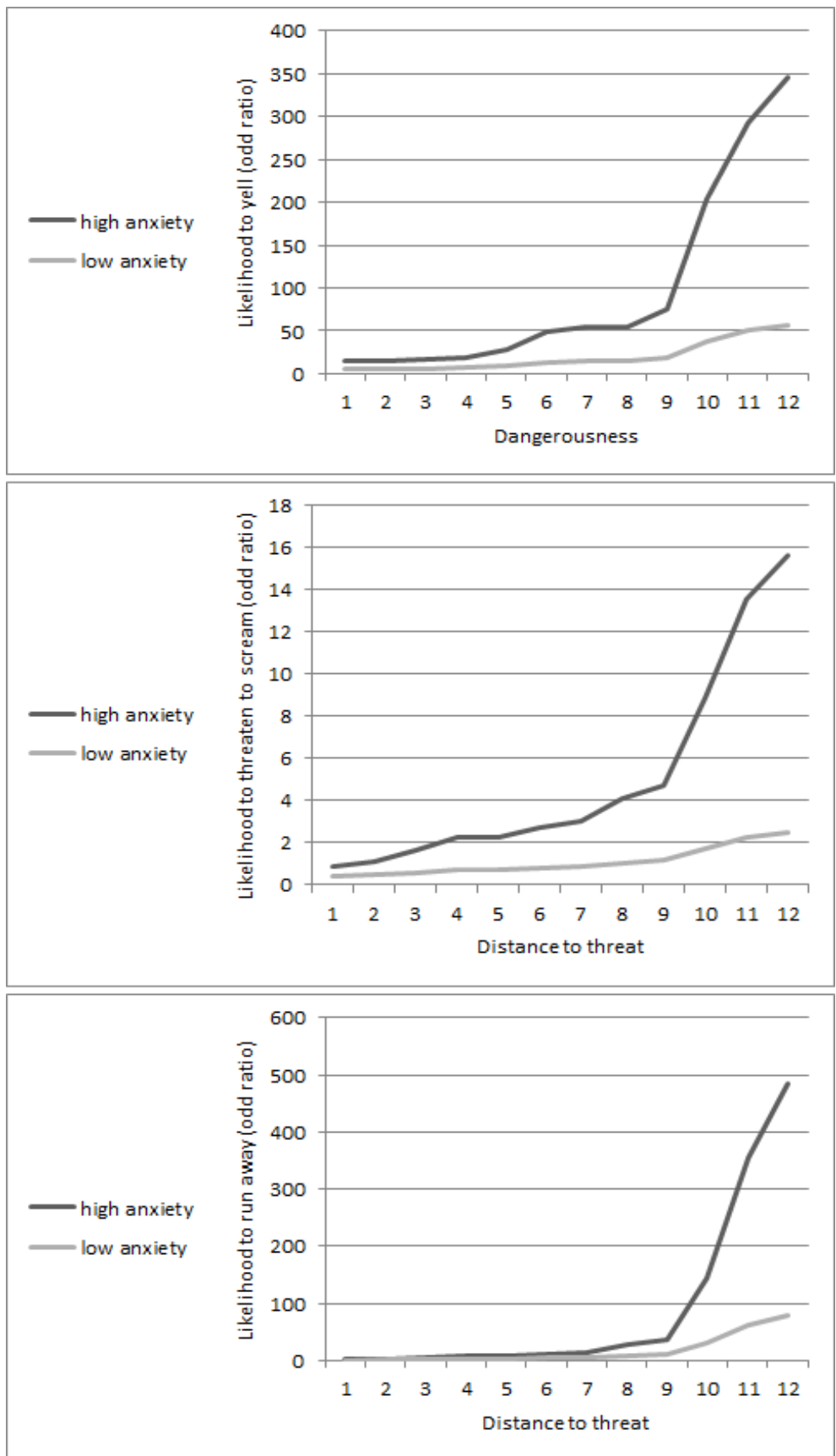

Figure 4. The effect of attachment anxiety and dangerousness on the likelihood to yell (top); the effect of anxiety and distance to threat on the likelihood to threaten to scream (middle); and the effect of anxiety and distance to threat on the likelihood to run away (bottom).

\footnotetext{
${ }^{4}$ Attachment avoidance also qualified the effects of dangerousness, escapability, distance from the threat, and concealment on participants' likelihood to yell. The pattern of results was similar to the qualifying effect of avoidance on clarity of threat.
} 


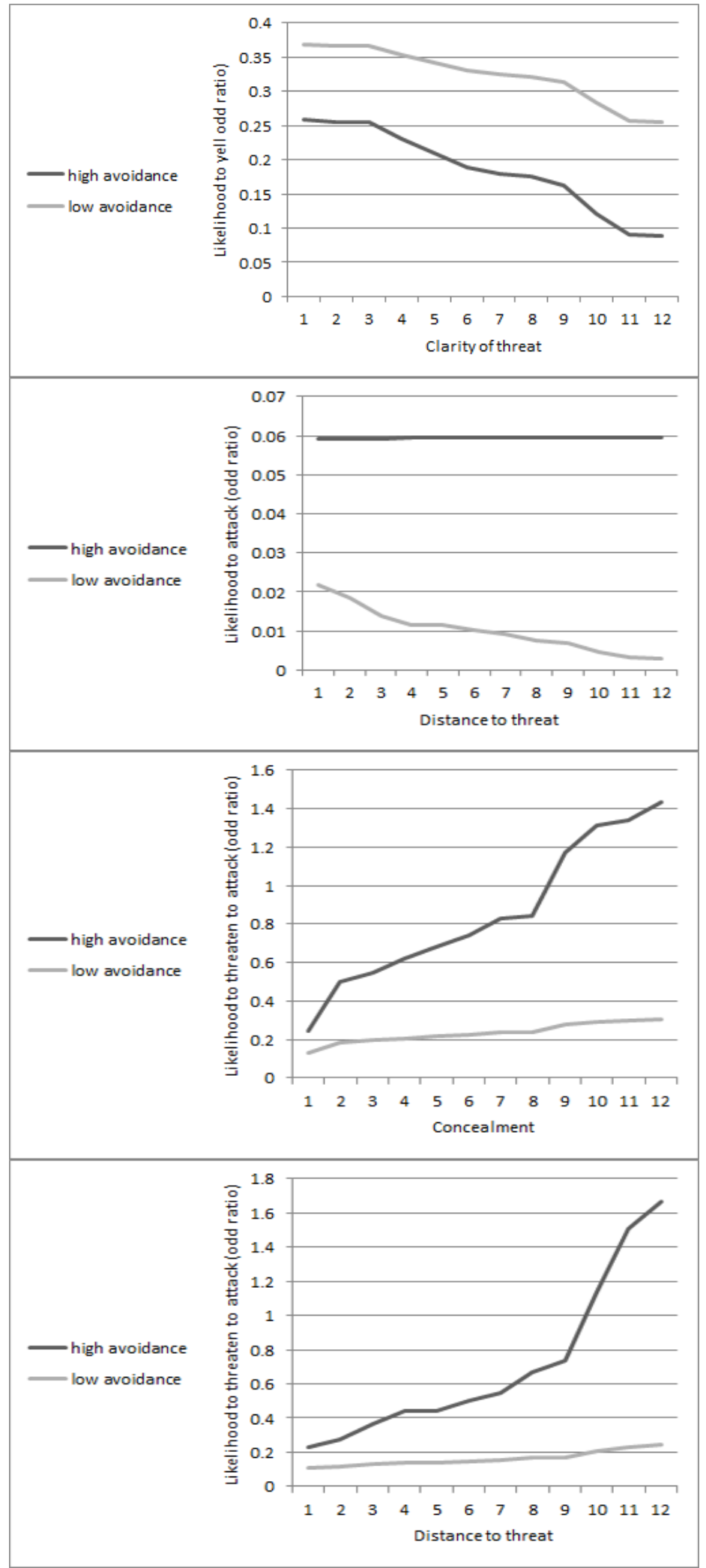

Figure 5. The effect of avoidance and clarity of threat on the likelihood to yell (top); the effect of avoidance and distance to threat on the likelihood to attack (middle a); the effect of avoidance and concealment on the likelihood to threaten to attack (middle a); and the effect of avoidance and distance on the likelihood to threaten to attack (bottom). 
Predicting rapid-responder and anxiety-related action tendencies. In this section, we examined whether attachment orientations (avoidance and anxiety) qualify the effects of situational features on participants' tendency to undertake rapid-responder (attack, threaten to attack) and anxiety-related (risk assessment, look for a weapon) actions. Unstandardized HLM coefficients and odd ratios are presented in Table 4.

Table 4

Unstandardized HLM Coefficients and Odd Ratios for the Effects of Attachment Orientations, and Situational Features on Participants' Rapid-Responder- and Anxiety-Related Action Tendencies (Study 2)

\begin{tabular}{|c|c|c|c|c|c|c|c|c|}
\hline & \multicolumn{6}{|c|}{ Rapid-responder-related } & \multirow{2}{*}{\multicolumn{2}{|c|}{$\begin{array}{l}\text { Anxiety-related } \\
\text { Risk assessment }\end{array}$}} \\
\hline & \multicolumn{2}{|c|}{ Attack } & \multicolumn{2}{|c|}{ Threaten to attack } & \multicolumn{2}{|c|}{ Look for a weapon } & & \\
\hline & $b$ & $\operatorname{Exp}(b)$ & $b$ & $\operatorname{Exp}(b)$ & $b$ & $\operatorname{Exp}(b)$ & $b$ & $\operatorname{Exp}(b)$ \\
\hline Dangerousness & $0.93^{* * *}$ & 2.53 & $0.12^{*}$ & 1.13 & $-0.24^{*}$ & 0.79 & $-1.41^{* * *}$ & 0.24 \\
\hline Being caught & $1.30^{* * *}$ & 3.67 & 0.06 & 1.07 & $-0.57^{* * *}$ & 0.57 & $-1.00^{* * *}$ & 0.37 \\
\hline Distance & $-1.47^{* * *}$ & 0.23 & $-0.26^{*}$ & 0.77 & $1.00^{* * *}$ & 2.71 & $0.72^{* * *}$ & 2.06 \\
\hline Clarity of the threat & $0.87^{* * *}$ & 2.38 & $0.21^{*}$ & 1.24 & $-0.16^{\sim}$ & 0.86 & $-1.91^{* * *}$ & 0.15 \\
\hline Concealment & $-1.18^{* * *}$ & 0.31 & $-0.12^{\sim}$ & 0.88 & $0.71^{* * *}$ & 2.03 & $1.00^{* * *}$ & 2.72 \\
\hline Anxiety & -0.18 & 0.81 & -0.28 & 0.76 & -0.01 & 0.99 & -0.12 & 0.88 \\
\hline Avoidance & 0.15 & 1.15 & 0.07 & 1.07 & -0.17 & 0.85 & 0.15 & 1.15 \\
\hline Fear of negative evaluation & -0.01 & 0.99 & -0.01 & 1.0 & 0.01 & 1.01 & -0.01 & 1.00 \\
\hline Body sensations & 0.02 & 1.02 & 0.11 & 1.11 & 0.06 & 1.07 & $-0.51^{* * *}$ & 0.60 \\
\hline Gender & $1.02^{* * *}$ & 2.77 & $0.97^{* * *}$ & 2.65 & $0.69^{* *}$ & 2.00 & $0.75^{* * *}$ & 2.11 \\
\hline Dangerousness X anxiety & $-0.36^{*}$ & 0.70 & 0.10 & 1.10 & 0.01 & 1.01 & -0.12 & 0.89 \\
\hline Being caught $X$ anxiety & $-0.43^{*}$ & 0.66 & 0.25 & 1.28 & 0.05 & 1.05 & -0.09 & 0.92 \\
\hline Distance $\mathrm{X}$ anxiety & $0.48^{*}$ & 1.62 & -0.02 & 0.98 & $-0.25^{*}$ & 0.79 & 0.05 & 1.05 \\
\hline Clarity of the threat $\mathrm{X}$ anxiety & $-0.29^{*}$ & 0.75 & -0.07 & 0.94 & -0.01 & 0.99 & -0.17 & 0.84 \\
\hline Concealment $\mathrm{X}$ anxiety & $0.41^{* *}$ & 1.51 & $-0.24^{*}$ & 0.77 & -0.13 & 0.88 & 0.04 & 1.04 \\
\hline Dangerousness $\mathrm{X}$ avoidance & 0.07 & 1.07 & -0.04 & 0.97 & -0.13 & 0.88 & 0.08 & 1.08 \\
\hline Being caught $\mathrm{X}$ avoidance & -0.01 & 0.99 & -0.18 & 0.83 & -0.10 & 0.91 & 0.04 & 1.04 \\
\hline Distance $\mathrm{X}$ avoidance & $0.29^{\sim}$ & 1.34 & $0.27^{*}$ & 1.31 & -0.06 & 0.94 & -0.14 & 0.86 \\
\hline Clarity of the threat $X$ avoidance & 0.01 & 1.01 & -0.05 & 0.95 & -0.11 & 0.89 & 0.01 & 1.02 \\
\hline Concealment $\mathrm{X}$ avoidance & 0.05 & 1.05 & $0.18^{*}$ & 1.20 & 0.08 & 1.08 & -0.08 & 0.92 \\
\hline
\end{tabular}

Notes. $\sim p<0.07,{ }^{*} p<0.05,{ }^{* *} p<0.01,{ }^{* * *} p<0.001 . D F(287,3507)$. Tolerance scores were above 0.4 .

Multilevel logistic regression analyses indicated that attachment avoidance qualified the effects of the situational features on people's likelihood to attack or to threaten to attack. As can be seen in Figure 5 (middle panel a), the likelihood of people low on attachment avoidance (and, therefore, more secure with respect to this domain) to attack was low and became lower as the distance from the threat increased. Conversely, the probability of people high on attachment avoidance to attack was significantly higher than their more secure counterparts, and it was not affected by the distance from the threat (i.e., remained high regardless of the distance). The likelihood of people low on avoidance to threaten to attack was low and was not affected by the possibilities for concealment (see Figure 5 , middle panel $b)^{5}$. In contrast, the probability of people high on attachment avoidance to threaten to attack was significantly higher than their more secure counterparts, and became higher as the possibilities for concealment became greater. An identical pattern of results was obtained regarding the qualifying effect of avoidance on the link between distance from the threat and the likelihood to

\footnotetext{
${ }^{5}$ Attachment anxiety also qualified the effects of dangerousness, escapability, distance from the threat, and concealment on participants' likelihood to attack. The pattern of results was similar to the qualifying effect of anxiety on clarity of threat.
} 
threaten to attack (see Figure 5, bottom panel).

Regarding attachment anxiety, the analyses indicated that the likelihood of people high on attachment anxiety to choose attacking as a first response was dependent on several situational features. For example, as can be seen in Figure 6 (top panel), the likelihood of people low on attachment anxiety (and, therefore, more secure with respect to this domain) to choose attacking was significantly higher than that of people high on attachment anxiety. In addition, the probability to attack was not dependent on the clarity of the threat among people low on anxiety. Conversely, this likelihood decreased as the nature of the threat became clearer among people high on attachment anxiety. In addition, the likelihood of people high on attachment anxiety to choose threatening to attack as a first response was dependent on the availability of places of concealment. Among people low on attachment anxiety, the probability to threaten to attack decreased as concealment places became more available. Conversely, the likelihood of people high on attachment anxiety to threaten to attack was significantly lower than their more secure counterparts, and it was virtually not affected by concealment (see Figure 6, middle panel). Finally, the likelihood of people high on attachment anxiety to choose looking for a weapon as a first response was dependent on the distance from the threat. Among people low on attachment anxiety, the probability to look for a weapon increased as the distance from the threat increased. Conversely, the likelihood of people high on attachment anxiety to look for a weapon was significantly lower than their more secure counterparts, and it was virtually not affected by the distance from the threat (i.e., remained low even when the distance from the threat was the highest; see Figure 6, bottom panel).

Overall, the findings supported our predictions and were in line with the results of Study 1. Attachment anxiety either increased the likelihood of choosing sentinel-related responses (in the case of begging) or interacted with the situational features to heightened people's probability of choosing these responses (in the case of yelling and threatening to scream). It also interacted with the situational features to increase people's tendency of running away (a fear-related response). Attachment anxiety was not linked with the tendency to hide. In addition, attachment anxiety interacted with the situational features to decrease the likelihood of choosing rapid-responder-related responses (specifically attacking and threatening to attack) and anxiety-related behaviors (specifically looking for a weapon). These effects were significant even after controlling for fear of negative evaluation, body sensations, and gender.

Attachment avoidance interacted with the situational features to heightened people's probability of choosing rapid-responder-related responses (specifically, attack and threatening to attack). In contrast to Study 1, attachment avoidance was not related to people's tendency for risk assessment (an anxiety-related response) or to the likelihood of choosing looking for a weapon as a first response. Attachment avoidance also either decreased the likelihood of choosing sentinel-related responses (in the case of begging) or interacted with the situational features to lowering people's probability of choosing these responses (in the case of yelling). Finally, attachment avoidance interacted with the situational features to heightened people's probability of choosing hiding as a first response (a fear-related response).

\section{General Discussion}

Throughout the ages, human beings and many nonhuman mammals have faced numerous threats. To overcome them, mammals have been perfected by evolution to respond to situational features in predictable ways (Blanchard, 1997). Over the course of mammalian evolution, several behavioral systems - as the attachment system-also emerged because they contributed to the likelihood of survival (Bowlby, 1973; 1982). The 
activation of these systems, specifically the attachment system, promotes the development of personality dispositions (i.e., attachment anxiety and avoidance), which affect people's reactions when dealing with threats (Ein-Dor, in press; Ein-Dor et al., 2010; Ein-Dor \& Perry, 2012). In the present research, we examined the interplay between personality and situational features in predicting people's action tendencies in times of threats and danger.
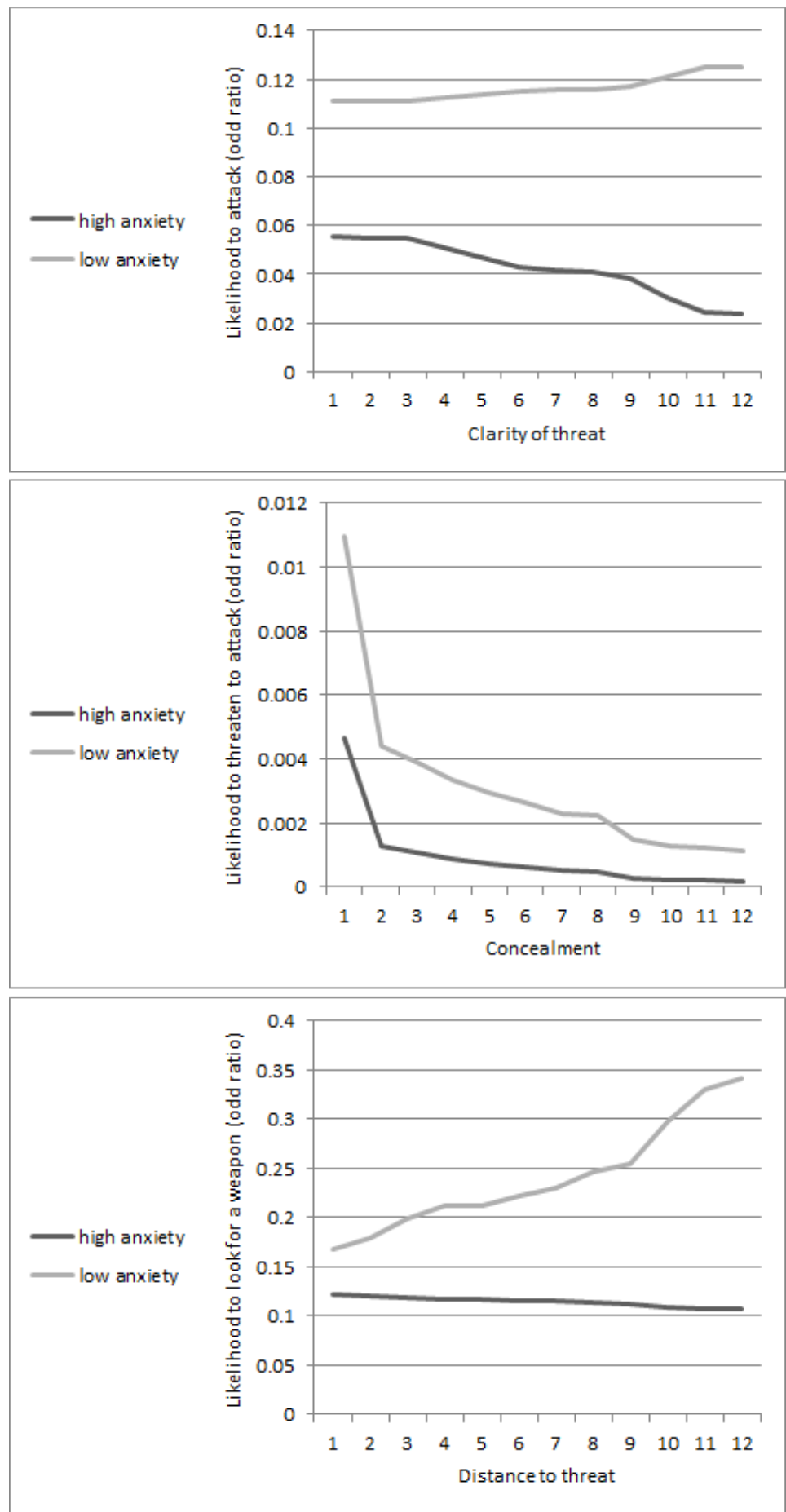

Figure 6. The effect of attachment anxiety and clarity of threat on the likelihood to attack (top); the effect of anxiety and concealment on the likelihood to threaten to attack (middle); and the effect of anxiety and distance to threat on the likelihood to look for a weapon (bottom). 
In line with SDT, we predicted that attachment anxiety would be linked with a greater tendency to demonstrate sentinel-related reactions in times of need as yelling, threatening to yell, and begging for help, as well as fear-related behaviors (Gray \& McNaughton, 2000) as running away and hiding. We also predicted that attachment anxiety would be related to a decrease in the likelihood to adopt rapid-responder-related reactions as attacking and threatening to attack, as well as anxiety-related behaviors (Gray \& McNaughton, 2000) as looking for a weapon and assessing the risk of the situation. Supporting this line of reasoning, we found in Studies 1 and 2 that attachment anxiety was linked with an overall tendency to choose begging as a first response regardless of the situational features, while interacting with the situational features to increase the likelihood of yelling and threatening to scream. Although these behaviors are sentinel-related, research contends that begging on one hand and yelling and threatening to scream on the other hand, have different origins. Begging has been most likely perfected by evolution because of sibling competition (e.g., Godfray \& Johnstone, 2000) as a way of soliciting parental resources, care, and support. Anxious attachment is organized around hyperactivating strategies of affecting regulation, which involves becoming very emotional and insistent in attempts to gain care and support from others (Cassidy \& Kobak, 1988; Feeney \& Noller, 1990; Shaver \& Mikulincer, 2002). Therefore, begging might be a response that people high on attachment anxiety adopt early on, and one that generalizes to other domains as responses to threats. Yelling and threatening to scream (also called defensive threat; Blanchard et al., 2001) were most likely evolved to deter potential harm-doers, to alert others to danger, and to call on others for help and care (e.g., Ein-Dor et al., 2010). Anxious people might elicit these behaviors because they are overwhelmed by tension and stress in times of need, and are over-dependent on others' help.

Attachment anxiety was also linked with a heightened tendency to run away but not to hide. Bowlby (1973) was the first to indicate that running away from threats has a complimentary action of moving toward attachment figures (i.e., seeking proximity to significant others while moving away from danger). Mawson (2005) noted that by running away, people not only distance themselves from threats but also advance toward familiar people and places. By hiding, people decrease the chances of getting hurt but do so without the aid of others. Thus, because people high on attachment anxiety cling to others and rely on them for support, running away from threats is more in line with their personality-related tendencies than hiding.

Finally, we found that attachment anxiety interacted with the situational features to decrease the likelihood of choosing rapid-responder-related responses (i.e., attacking and threatening to attack) and anxiety-related behaviors (e.g., looking for a weapon). Rapid-responder- and anxiety-related reactions require high self-efficacy and self-reliance. Anxious individuals have low self-reliance and deficient sense of self-worth (e.g., Mikulincer, Shaver, \& Pereg, 2003). Therefore, it is more likely that they will adopt sentinel-related action tendencies than rapid-responder- or anxiety-related ones.

Regarding attachment avoidance, we predicted that it would be linked with a greater tendency to adopt rapid-responder-related reactions in times of need as attacking and threatening to attack. We also hypothesized that it would be related to anxiety-related behaviors (Gray \& McNaughton, 2000) as looking for a weapon and assessing the risk of the situation, and to fear-related actions (Gray \& McNaughton, 2000) as running away and hiding. In addition, we predicted that it would be associated with a decrease in the likelihood to demonstrate sentinel-related reactions as yelling, threatening to yell, and begging for help. Supporting this line of reasoning, we found in Studies 1 and 2 that attachment avoidance is linked with a heightened tendency for rapid-responder-related reactions as attacking and threatening to attack (which relate to "fight" responses) as 
well as with running away (which relates to a "flight" response). These responses correspond with the fear system (Gray \& McNaughton, 2000; McNaughton \& Corr, 2004). SDT posits that attachment-based responses in times of need may be seen as the social component of the fear system —orienting people not only away from threats but also toward helpful others. Hyperactivating the attachment system (as in attachment anxiety) would promote over-dependence on others (i.e., because of the excessive activation of the social component of the fear system). Deactivating the attachment system (as in attachment avoidance) would bolster "compulsive self-reliance" (Bowlby, 1973) and focus on self-protective fight-or-flight reactions (i.e., because of the deactivation of the social component of the fear system).

The results regarding the links between attachment avoidance and anxiety-related reactions (i.e., risk assessment) and between attachment avoidance and sentinel-related tendencies were equivocal. The association between attachment avoidance and anxiety-related reactions was found among Israeli participants (Study 1), but not among participants from other Western cultures (Study 2). Conversely, the association between attachment avoidance and sentinel-related tendencies was found among participants from Western cultures (Study 2), but not among Israeli participants (Study 1). Thus, it seems that these associations are affected by cultural differences, as was documented in other responses to emotional-provoking events (see Mesquita \& Frijda, 1992 for a review). We believe that these differences may be the result of the political tension in Israel (Bar-Tal et al., 2010). Israeli participants who were high in attachment avoidance were more likely to assess the risk of the situation than more secure individuals, and to share the same level of vigilance as secure people (i.e., similar sentinel-related tendencies). Participants high in attachment avoidance from cultures with less political violence than Israel, tended to be less vigilant than secure people, and to maintain the same likelihood for risk assessment. Risk assessment and adequate levels of vigilance seem to be more productive to Israelis than to people from other cultures.

Our findings also indicated that attachment orientations interacted with all of the situational features without a specific pattern of results. Personality dispositions seem to orient people toward robust tendencies (as in sentinel or rapid-responder) by affecting the way people perceive and respond to various situational features. Nevertheless, the situational features appear to have a greater influence on people's actions in times of threats and danger than their personality dispositions, as was apparent by the effect sizes of these constructs.

There are, of course, some limitations to our research. First, because of ethical considerations, we were unable to expose participants to actual threats. Therefore, we used threat scenarios. Although there might be differences between action tendencies and actual reactions in times of threats and danger, research has indicated that scenarios have high predictive validity (e.g., Barber, Foley, \& Jones, 1999; Erber, Szuchman, \& Prager, 2001), and that they can elicit considerable emotional and physiological reactions (e.g., Bernat, Calhoun, \& Adams, 1999; Conklin, Tiffany, \& Vrana, 2000). Second, people's reactions to threats are influenced not only by situational features or by their personality but also by the presence of other people around them. These group-level behaviors were beyond the scope of the present research. This limitation is addressed to some extent by recent research showing that people high in attachment anxiety demonstrate sentinel-related behaviors in response to an experimentally manipulated threat (Ein-Dor et al., 2011b; Ein-Dor \& Orgad, 2012), and that people high in attachment avoidance adopt rapid-responder-related behaviors during such times (Ein-Dor et al., 2011b). These reactions also promoted the effectiveness of groups in dealing with threats by indicating that diverse groups with respect to attachment were more competent than less diverse groups when facing an experimentally manipulated threat. Third, we employed a correlational design in our studies that 
precludes confident conclusions about the direction of causality in the links between attachment orientations and people's reactions to threat scenarios. Theory and research on attachment, however, indicate that attachment orientations are formed in early childhood and are moderately stable over periods of years (see Mikulincer \& Shaver, 2007 for a review). Thus, we believe that it is more likely that attachment orientations influence people's reactions to threats and not vice versa.

Despite the limitations, our findings add to the literature on humans' reactions to threat and danger by highlighting the possible interplay between situational features and personality dispositions. Studies like the ones reported here may offer a new perspective on the evolved mechanisms that promoted the survival of our ancestors in the course of mammalian evolution.

\section{References}

Aiken, L. S., \& West, S. G. (1991). Multiple regression: Testing and interpreting interactions. Newbury Park, London, Sage.

Alexander, R., Feeney, J., Hohaus, L., \& Noller, P. (2001). Attachment style and coping resources as predictors of coping strategies in the transition to parenthood. Personal Relationships, 8, 137-152.

Bar-Tal, D., Halperin, E., \& Oren, N. (2010). Socio-psychological barriers to peace making: The case of the israeli jewish society. Social Issues and Policy Review, 4, 63-109.

Barber, M. E., Foley, L. A., \& Jones, R. (1999). Evaluations of aggressive women: The effects of gender, socioeconomic status, and level of aggression. Violence and Victims, 14, 353-363.

Bernat, J. A., Calhoun, K. S., \& Adams, H. E. (1999). Sexually aggressive and non-aggressive men: Sexual arousal and judgements in response to acquaintance rape and consensual analogues. Journal of Abnormal Psychology, 108, 662-673.

Blanchard, D. C. (1997). Stimulus and environmental control of defensive behaviors. In M. Bouton, \& M. Fanselow (Eds.), The functional behaviorism of Robert C. Bolles: Learning, motivation and cognition (pp. 283-305). Washington, D.C.: American Psychological Association.

Blanchard, D. C., Hynd, A. L., Minke, K. A., Minemoto, T., \& Blanchard, R. J. (2001). Human defensive behaviours to threat scenarios show parallels to fear and anxiety-related defence patterns of non-human mammals. Neuroscience and Biobehavioral Reviews, 25, 761-770.

Blanchard, R. J., Blanchard, D. C., \& Hori, K. (1989). Ethoexperimental approaches to the study of defensive behaviour. In R. J. Blanchard, P. F. Brain, D. C. Blanchard, \& S. Parmigiani (Eds.), Ethoexperimental approaches to the study of behaviour (pp. 114-136). Dordrecht: Kluwer Academic Publishers.

Bowlby, J. (1973). Attachment and loss: Vol. 2. Separation: Anxiety and anger. New York: Basic Books.

Bowlby, J. (1980). Attachment and loss: Vol. 3. Sadness and depression. New York: Basic Books.

Bowlby, J. (1982). Attachment and loss: Vol. 1. Attachment (2nd ed.). New York: Basic Books.

Bowlby, J. (1988). A secure base: Clinical applications of attachment theory. London: Routledge.

Brennan, K. A., Clark, C. A., \& Shaver, P. R. (1998). Self-report measurement of adult attachment: An integrative overview. In J. A. Simpson, \& W. S. Rholes (Eds.), Attachment theory and close relationships (pp. 46-76). New York: Guilford.

Campbell, C. (1986). Images of war: A problem in San rock art research. World Archaeology, 18, 255-268. doi: 10.1080/00438243.1986.9980002

Casey, L. M., Oei, T. P. S., Newcombe, P. A., \& Kenardy, J. (2004). The role of catastrophic misinterpretation of bodily sensations and panic self-efficacy in predicting panic severity. Anxiety Disorders, 18, 325-340.

Cassidy, J., \& Kobak, R. R. (1988). Avoidance and its relationship with other defensive processes. In J. Belsky, \& T. Nezworski (Eds.), Clinical implications of attachment (pp. 300-323). Hillsdale, N.J.: Erlbaum.

Chambless, D. L., Caputo, C. G., Bright, P., \& Gallagher, R. (1984). Assessment of fear of fear in agoraphobics: The body sensations questionnaire and the agoraphobic cognitions questionnaire. Journal of Consulting and Clinical Psychology, 52, 1090-1097.

Collins, N. L., \& Read, S. J. (1990). Adult attachment, working models, and relationship quality in dating couples. Journal of Personality and Social Psychology, 58, 644-663.

Conklin, C. A., Tiffany, S. T., \& Vrana, S. R. (2000). The impact of imagining completed versus interrupted smoking on cigarette craving. Experimental and Clinical Psychopharmacology, 8, 68-74. 
Ein-Dor, T. (in press). Social defense theory: How a mixture of personality traits in group contexts may promote our survival. In M. Mikulincer, \& P. R. Shaver (Eds.), Nature and development of social connections: From brain to group. Washington, D.C.: American Psychological Association.

Ein-Dor, T., Mikulincer, M., Doron, G., \& Shaver, P. R. (2010). The attachment paradox: How can so many of us (the insecure ones) have no adaptive advantages? Perspectives on Psychological Science, 5, 123-141.

Ein-Dor, T., Mikulincer, M., \& Shaver, P. R. (2011a). Attachment insecurities and the processing of threat-related information: Studying the schemas involved in insecure people's coping strategies. Journal of Personality and Social Psychology, 101, 78-93. doi: 10.1037/a0022503

Ein-Dor, T., Mikulincer, M., \& Shaver, P. R. (2011b). Effective reaction to danger: Attachment insecurities predict behavioral reactions to an experimentally induced threat above and beyond general personality traits. Social Psychological and Personality Science, 2, 467-473.

Ein-Dor, T., \& Orgad, T. (2012). Scared saviors: Evidence that people high in attachment anxiety are more effective in alerting others to threat. European Journal of Social Psychology, 42, 667-671.

Ein-Dor, T., \& Perry, A. (2012). Diversity is bliss: How a mixture of personality traits in group contexts may promote our survival. In B. O. Hunter, \& T. J. Romero (Eds.), Psychology of threat (pp. 55-74). Hauppauge, N.Y.: Nova Science Publishers, Inc..

Ein-Dor, T., \& Perry, A. (2014). Full house of fears: Evidence that people high in attachment anxiety are more accurate in detecting deceit. Journal of Personality, 82, 83-92.

Erber, J. T., Szuchman, L. T., \& Prager, I. G. (2001). Ain’t misbehaving: The effect of age and intentionality on judgements about misconduct. Psychology and Aging, 16, 85-95.

Feeney, B. C., \& Collins, N. L. (2001). Predictors of caregiving in adult intimate relationships: An attachment theoretical perspective. Journal of Personality and Social Psychology, 80, 972-994.

Feeney, J. A., \& Noller, P. (1990). Attachment style as a predictor of adult romantic relationships. Journal of Personality and Social Psychology, 58, 281-291.

Fraley, R. C., \& Shaver, P. R. (1997). Adult attachment and the suppression of unwanted thoughts. Journal of Personality and Social Psychology, 73, 1080-1091.

Fraley, R. C., \& Shaver, P. R. (2000). Adult romantic attachment: Theoretical developments, emerging controversies, and unanswered questions. Review of General Psychology, 4, 132-154.

Godfray, H. C. J., \& Johnstone, R. A. (2000). Begging and bleating: The evolution of parent—offspring signalling. Philosophical Transactions of the Royal Society B, 355, 1581-1591.

Gray, J. A., \& McNaughton, N. (2000). The neuropsychology of anxiety. Oxford: Oxford University Press.

Hamilton, W. D. (1964). The genetical evolution of social behaviour: I and II. Journal of Theoretical Biology, 7, 1-52.

Hazan, C., \& Zeifman, D. (1999). Pair-bonds as attachments: Evaluating the evidence. In J. Cassidy, \& P. R. Shaver (Eds.), Handbook of attachment: Theory, research, and clinical applications (pp. 336-354). New York: Guilford.

Leary, M. R. (1983). A brief version of the fear of negative evaluation scale. Personality and Social Psychology Bulletin, 9 , 371-375.

Mawson, A. R. (2005). Understanding mass panic and other collective responses to threat and disaster. Psychiatry: Interpersonal \& Biological Processes, 68, 95-113.

McNaughton, N., \& Corr, P. J. (2004). A two-dimensional neuropsychology of defense: Fear/anxiety and defensive distance. Neuroscience and Biobehavioral Reviews, 28, 285-305.

Mesquita, B., \& Frijda, N. H. (1992). Cultural variations in emotions: A review. Psychological Bulletin, 112, $179-204$.

Mikulincer, M., Birnbaum, G., Woddis, D., \& Nachmias, O. (2000). Stress and accessibility of proximity-related thoughts: Exploring the normative and intraindividual components of attachment theory. Journal of Personality and Social Psychology, 78, 509-523.

Mikulincer, M., Gillath, O., \& Shaver, P. R. (2002). Activation of the attachment system in adulthood: Threat-related primes increase the accessibility of mental representations of attachment figures. Journal of Personality and Social Psychology, 83, 881-895.

Mikulincer, M., Hirschberger, G., Nachmias, O., \& Gillath, O. (2001). The affective component of the secure base schema: Affective priming with representations of attachment security. Journal of Personality and Social Psychology, 81, 305-321.

Mikulincer, M., \& Shaver, P. R. (2007). Attachment in adulthood: Structure, dynamics, and change. New York: Guilford Press. 
Mikulincer, M., Shaver, P. R., \& Pereg, D. (2003). Attachment theory and affect regulation: The dynamics, development, and cognitive consequences of attachment-related strategies. Motivation and Emotion, 27, 77-102.

Perkins, A. M., \& Corr, P. R. (2006). Reactions to threat and personality: Psychometric differentiation of intensity and direction dimensions of human defensive behaviour. Behavioural Brain Research, 169, 21-28.

Raudenbush, S. W., Bryk, A. S., \& Congdon, R. (2004). HLM 6 for Windows (Computer software). Skokie, I.L.: Scientific Software International, Inc..

Rom, E., \& Mikulincer, M. (2003). Attachment theory and group processes: The association between attachment style and group-related representations, goals, memories, and functioning. Journal of Personality and Social Psychology, 84, 1220-1235.

Schlenker, B. R. (1980). Impression management: The self-concept, social identity, and interpersonal relations. Monterey, C.A.: Brooks/Cole.

Shaver, P. R., \& Mikulincer, M. (2002). Attachment-related psychodynamics. Attachment and Human Development, 4, $133-161$.

Spielberger, C. D., Gorsuch, R. L., \& Lushene, R. E. (1970). Manual for the State-Trait Anxiety Inventory. Palo Alto, C.A.: Consulting Psychologists Press.

Van Lange, P. A. M., Otten, W., De Bruin, E. M. N., \& Joireman, J. A. (1997). Development of prosocial, individualistic, and competitive orientations: Theory and preliminary evidence. Journal of Personality and Social Psychology, 73, 733-746. 